NBER WORKING PAPER SERIES

\title{
TEMPORARY SHOCKS AND UNAVOIDABLE TRANSITIONS TO A HIGH-UNEMPLOYMENT REGIME
}

\author{
Wouter J. Den Haan \\ Working Paper 9349 \\ http://www.nber.org/papers/w9349 \\ NATIONAL BUREAU OF ECONOMIC RESEARCH \\ 1050 Massachusetts Avenue \\ Cambridge, MA 02138 \\ November 2002
}

I would like to thank the European Central Bank for its support and hospitality and Yann Algan, Jim Hamilton, John Hassler, Assar Lindbeck, Michael Kiley, Jim Mitchell, Torsten Persson, Garey Ramey, Valerie Ramey, Richard Rogerson, Francisco Ruge-Murcia, Kjetil Storesletten, Joel Watson, and Fabrizio Zilibotti for helpful comments. The views expressed herein are those of the authors and not necessarily those of the National Bureau of Economic Research.

(C) 2002 by Wouter J. DenHaan. All rights reserved. Short sections of text, not to exceed two paragraphs, may be quoted without explicit permission provided that full credit, including (C) notice, is given to the source. 
Temporary Shocks and Unavoidable Transitions to a High-Unemployment Regime Wouter J. Den Haan

NBER Working Paper No. 9349

November 2002

JEL No. D50, C62, E24, E62, J64

$\underline{\text { ABSTRACT }}$

This paper develops a model with multiple steady states (low tax and low unemployment versus high tax and high unemployment) in which equilibrium selection is not conditioned on a sunspot variable. Instead, large temporary shocks initiate unavoidable transitions from one steady state to another. Tax policies have huge effects in some cases. In particular, it is possible that the transition to the high-unemployment steady state after a negative shock can be avoided if the government borrows to finance unemployment benefits, and in some cases it is even possible that a credible permanent tax cut would force the economy out of the high-unemployment steady state. The model is used to explain the high European unemployment rates in the 80's and 90's. The paper argues that the increase in unemployment during the 70's played a key role because it led to an increase in the obligation to pay unemployment benefits. The implied tax burden was so big that the transition to the high-unemployment regime was the unique equilibrium outcome.

\author{
Wouter J. Den Haan \\ Department of Economics \\ University of California, San Diego \\ La Jolla, CA 92093-0508 \\ NBER and CEPR \\ wdenhaan@ucsd.edu
}




\section{Introduction}

Models with both a high-activity and a low-activity steady-state equilibrium that are sustained by macroeconomic complementarities have played an important role in modern macroeconomics. Exemplary papers that model this idea are Bryant (1983) and Cooper and John (1988). A drawback of this literature is that in a dynamic framework the switching between the two regimes is typically conditioned on a sunspot variable. Relying on sunspot variables is undesirable because they are hard to identify and the sign of the effect of the sunspot variable is indeterminate. ${ }^{1}$ This paper contributes to this literature by providing a framework in which temporary changes in productivity, through its effect on the stock of unemployed, control the dynamics of the system. In particular, temporary shocks can induce an inevitable transition from one steady state to another. ${ }^{2}$

In this paper we develop a labor market matching model with a low and a high-unemployment steady state. Matching models are ideally suited to embed the multiplicity idea in a dynamic framework because they carefully model the transition from unemployment to employment as well as the transition from employment to either unemployment or to employment at a different productivity level. The reason for the multiplicity is very simple. In one steady-state, unemployment rates are low and, consequently the government's obligations to pay unemployment benefits are low. This implies a low tax burden. Low tax rates correspond to low breakup margins of existing jobs, low rejection margins of new jobs, and indeed a low unemployment rate. In the other steady-state, high tax rates imply high breakup and rejection margins and, thus, high unemployment rates. We will show that it is possible that both steady states are unique continuation equilibria in the sense that the belief to move to the other steady state is not self-fulfilling.

If steady states are unique continuation equilibria, then the economy will converge back to the original steady state after a small shock. If the shock is large enough, however, this is not the case. The idea is the following. Suppose the economy is in the low-unemployment steady state and in response to a one-time negative shock there is a wave of job destruction and an increase in the unemployment rate. Because of the matching friction unemployment will be high in some of the ensuing time periods as well. The increase in the number of unemployed would increase the liability of the government to pay benefits even if the economy would converge

\footnotetext{
${ }^{1}$ For example, in a model in which nominal money surprises have no or little effect, they still could serve as a sunspot variable such that a positive monetary surprise shock has a positive effect on output. In general, however, an equally valid solution is the one where a positive monetary surprise has a negative effect on output. See Farmer (1997).

${ }^{2}$ In Den Haan, Ramey, and Watson (2002), the number of relationships serves a similar role, that is, a large enough decline in the number of relationships necessarily leads to a total collapse.
} 
back to the good steady state, that is, even if future job creation and job destruction decisions are not affected. If the increase in the number of unemployed and the magnitude of unemployment benefits are high enough, however, the implied increase in tax rates does lead to an increase in the destruction rate of continuing relationships and an increase in the rejection rate of new matches. In other words, tax rates are too high for them not to affect job creation and job destruction. Consequently, the economy cannot convergence back towards the low-unemployment steady state and it has to converge towards the high-unemployment steady state. For intermediate shocks multiple equilibrium time paths are possible and the economy could either converge back to the low-unemployment steady state or converge to the high-unemployment steady state.

Transitions are not symmetric and in general it will be harder to switch to the low-unemployment steady state than to switch to the high-unemployment steady state. One reason is that relationships can be instantaneously terminated but creation of new relationships takes time. In addition, because matching takes time, the decrease in the discounted value of the government's promise to pay unemployment benefits when a positive shock occurs (after which the unemployment rate decreases gradually) will be smaller than the increase in the discounted value of the government's promise when a negative shock occurs (after which the unemployment rate increases instantaneously).

The paper also analyzes the importance of fiscal policy and in particular the effects of substituting debt for taxes to finance unemployment benefits. ${ }^{3}$ Consider the case where the economy is in the high-unemployment steady state and unemployment benefits are financed out of current-period taxes. Also, suppose that staying in the steady state is the unique continuation equilibrium under this tax policy. To understand why this could be the unique equilibrium time path suppose to the contrary that the rejection rate of newly matched pairs and the destruction rate are equal to zero and the economy will, thus, converge towards the low-unemployment steady state. Along the transition path unemployment and tax rates decrease, but because of the matching friction this process will take time. If the initial reduction in tax rates is not large enough then a zero rejection rate for new job offers would not be consistent with optimizing behavior and the described path with zero rejections would, thus, not be an equilibrium outcome. If the government starts out with a larger tax reduction, however, and initially finances transfers to the unemployed by issuing debt then the transition out of the high-unemployment steady

\footnotetext{
${ }^{3}$ The model does not satisfy Ricardian Equivalence because productive income and unemployment benefits are taxed at different rates and the comparison of current and future after-tax income from a productive relationship with current and expected unemployment benefits is key for the job destruction and job creation decision.
} 
state could-at least in some cases-be an equilibrium. ${ }^{4}$ Moreover, we will argue that if the tax cut is credible, then this transition out of the high-unemployment steady state would be the unique time path. Similarly, fiscal policy plays a key role in determining whether the economy can converge back to the low-unemployment steady state after a negative shock. In standard models, changes in tax rates only have big effects if supply elasticities have unrealistically large values. Here tax rates affect the breakup and rejection decision, however, and the effects are big if the mass of marginal jobs is big.

This paper is related to Morris and Shin (2000). In this paper the authors modify a model on bank runs with a low-withdrawal and a high-withdrawal steady state, such that the outcome is uniquely determined by the value of the fundamental variable. ${ }^{5}$ There is still a sense of having two regimes because the fraction of withdrawals is a discontinuous function of the fundamental state variable. In contrast, in this paper there still are two steady-state equilibria in which all fundamental exogenous variables have the same values. The time paths, however, are typically (but not always) unique. Whether the economy is on a time path towards the low-unemployment or the high-unemployment steady state is determined by the magnitude of the unemployment rate and, thus, by current and past realizations of the fundamental variables.

We show that the model can be used to explain the high European unemployment rates in the last two decades. During the 1950's and 1960's, the unemployment rate in both Europe and the U.S. was on average below five percent and was in the U.S. somewhat higher than in Europe. In response to steep increases in oil prices unemployment increased sharply during the 1970's on both continents. In Europe unemployment rates remained high in the two following decades, while in the U.S. they returned to their earlier low levels. The divergent behavior has been termed the "European unemployment puzzle". Obviously, a variety of institutional factors distinguishes Europe from the U.S., including strong unions, minimum wages, generous unemployment benefits, and high employment protection. These institutional distinctions cannot by themselves explain the differences in unemployment rates observed during the last two decades since they have been present throughout the postwar era. Several recent papers explain the European unemployment puzzle with models in which unemployment rates remain low in the presence of "employment-unfriendly" institutions as long as economic conditions are good but

\footnotetext{
${ }^{4}$ We will see that it is also possible that the present value of all the unemployment benefits the government has to finance during the transition is so high that there is no feasible deficit management for which transition out of the high-unemployment steady state is an equilibrium.

${ }^{5}$ The authors study a model with patient and impatient consumers that have to determine wether or not to withdraw time deposits.
} 
in which they increase if conditions deteriorate. ${ }^{6}$ In contrast, in countries with "employment-friendly" institutions the unemployment rate remains low if economic conditions deteriorate. Similarly, in this paper the high-unemployment steady state does not exist if the replacement rate (i.e., the level of unemployment benefits to the predisplacement wage level) is low. In this paper the wedge between taxes on productive income and unemployment benefits increases when the economy moves from the low-unemployment steady state to the high-unemployment steady state. This is exactly the deterioration in economic conditions used in Daveri and Tabellini (2000) to explain the European unemployment puzzle using both an empirical analysis and a theoretical model. Although similar in spirit, this paper distinguishes itself from the literature in two important aspects. First, the long-term changes predicted by the model proposed here are not in response to an unexplained change in an exogenous variable, ${ }^{7}$ but are the endogenous response to a temporary shock. Second, in this paper the 1970's play a key role in the explanation of the behavior of European unemployment rates in the 1980's and 1990's. In particular, in the proposed model a large enough increase in the number of unemployed, such as the increase observed during the 1970's necessarily leads to a new steady-state with high unemployment. This paper provides a formal model of the view in Lindbeck (1996) that "... once high unemployment has emerged, basic structures and mechanisms in West European societies tend to perpetuate it."

An explanation of the high European unemployment rates in the last two decades without assigning a role to the severe recession of the 1970's seems unsatisfactory, since European unemployment rates reached their extraordinarily high levels during the 1970's. One wonders whether the deep downturn in the 1970's simply delivered a shock to the European economic system from which it couldn't automatically recover. Most economists would agree that monetary policy and/or the increases in oil prices are key in explaining the behavior of real activity during the 1970's; the economic downturn during this decade cannot be explained solely by long-term

\footnotetext{
${ }^{6}$ Different candidates for the exogenous change in the economic environment are given in the literature. Ljungqvist and Sargent (1998) consider a long-term rise in economic turbulence, manifested in greater skill loss for displaced workers; Marimon and Zilibotti (1999) consider skill-biased technology improvements; Mortensen and Pissarides (1999) consider an increase in the variability of idiosyncratic productivity shocks; Daveri and Tabellini (2000) consider an increase in the tax wedge between labor income and unemployment benefits; Hornstein, Krusell, and Violante (2000) consider a long-term increase in embodied productivity; and Den Haan, Haefke, and Ramey (2001) consider a long-term rise in real interest rates, an increase in tax rates, and a decrease in the growth rate of disembodied total-factor-productivity.

${ }^{7}$ This is not supposed to mean that (exogenous) changes in, for example, TFP growth rates did not occur and are not part of the explanation to the European unemployment puzzle. To simplify the discussion, however, these effects are not included in the model.
} 
changes in the factors proposed in the literature. Of course, this argument doesn't refute the possibility that these long-term changes in the economic environment just happened to take effect around a period of prolonged economic downturn and if so it definitely seems plausible that the recession sped up the transition to the new steady state. Another possibility is that the events in this turbulent decade were in itself instrumental in bringing about long-term changes. For example, the increase in oil prices led in many countries to inflationary policies which later in the decade were followed by stringent contractionary policies. It seems sensible to assume that the resulting increase in inflationary uncertainty pushed real interest rates higher, which worsens economic conditions, although one wonders why the effect would be so persistent. Also, if different industry sectors have different TFP growth rates then the substitution processes observed after the increases in the oil price may very well have changed aggregate TFP growth rates. At best, however, the cited studies are incomplete by treating the 1950's and 1960's as one steady state, the 1980's and 1990's as another steady state, and ignoring the experience of the 1970's. The view expressed in this paper is that we are missing some essential elements of the solution to the puzzle if one simply views the 1970's as the transition phase from one steady-state to another.

This paper is organized as follows. In Section 2 we develop the benchmark model. Section 3 discusses the steady states, and Section 4 considers the response of the economy to small and large temporary shocks. In Section 5 we describe the European unemployment puzzle and argue that the explanation given in this paper fits the data well.

\section{Model}

The model used in this paper is a job market matching model similar to the one developed in Mortensen and Pissarides (1994). In Section 2.1 we describe the productive relationship between a worker and an entrepreneur, in Section 2.2 we describe the matching market, in Section 2.3 we define the surplus, in Section 2.4 we describe fiscal policy, and in Section 2.5 we give the equilibrium conditions. In Section 2.6, we introduce a version of the model with creation and destruction costs.

\subsection{Employment Relationships}

Production takes place within employment relationships consisting of one worker and one firm, who interact through discrete time until the relationship is severed. In this economy there are low-productivity relationships with low-skilled workers and highproductivity jobs with high-skilled workers. To simplify the model the skill level 
of a worker is given at birth and fixed throughout the worker's life. A relationship produces output $z$ per period, where $z$ is a stochastic variable and the three possible realizations for $z$ satisfy $z_{l, 1}<z_{l, 2}<z_{h}$. Low-productivity relationships can only attain values of $z_{l, 1}$ and $z_{l, 2}$ and when such a relationship is first formed, an initial value equal to $z$ is drawn with probability $p^{n}(z)$. For ongoing low-productivity relationships the probability that next period's value of $z$ is equal to $z_{l, j}$ when the current value of $z$ is given by $z_{l, i}$ is given by the transition function $p\left(z_{l, j} \mid z_{l, i}\right)$ with $i, j \in\{1,2\}$. New and continuing relationships with a high-skilled worker always produce $z_{h}$.

Both types of relationships may experience an exogenous breakup that occurs with probability $\rho_{l}^{x}$ for low-skilled workers and with probability $\rho_{h}^{x}$ for high-skilled workers. Exogenous breakups reflect events that permanently destroy the productivity of the relationship, e.g., market conditions may shift adversely. Alternatively, exogenous breakups can capture changes in workers' personal circumstances that lead them to change jobs. Assume that exogenous separations cannot occur in the period that a relationship is newly formed. After the current-period productivity parameter is determined, the worker and firm decide whether to continue or sever their relationship. If the worker and firm agree to sever their relationship following a switch, or if exogenous separation occurs, then they each enter a matching market in which new employment relationships are formed. In addition, workers and entrepreneurs are subject to shocks that induce retirement, occurring at the end of a period. Let $\rho^{r}$ denote the probability of retirement. For simplicity we assume that a retirement shock hits both partners in the relationship simultaneously. A retiring agent leaves the labor market and obtains a future value of zero.

\subsection{Matching Market}

New employment relationships are formed on a matching market. In our model there are low and high-productivity workers and entrepreneurs with projects for either lowproductivity or high-productivity workers. ${ }^{8}$ We assume that low-productivity and high-productivity workers find jobs on separate matching markets and there is a unit mass of workers and a unit mass of entrepreneurs. The fraction of low-productivity workers in the labor force $\phi$, is equal to the fraction of low-productivity projects. Whether a worker has low or high productivity is determined at birth and cannot be changed. These assumptions imply that in both matching markets the ratio of the mass of unemployed to the mass of vacancies is constant. This together with the assumption of a homogeneous of degree one matching function implies fixed match-

\footnotetext{
${ }^{8}$ For simplicity we assume that low-productivity workers are not productive in a highproductivity project and vice versa.
} 
ing probabilities. For low-productivity workers the matching probability is denoted by $\lambda_{l}$ and for the high-productivity workers by $\lambda_{h}$. Each period, a proportion $\rho^{r}$ of the workers leaves the labor force through retirement, replaced by an identical number of new entrants that flow into the unemployment pool. ${ }^{9}$ Further, established workers enter the unemployment pool when their employment relationships are severed. While they are unemployed, workers receive unemployment benefits equal to $r_{k}$ and a not-taxable benefit representing the disutility of working equal to $b_{k}$, with $k \in\{l, h\}$.

\subsection{Surplus Level}

A worker and entrepreneur in an ongoing relationship choose to continue their relationship if the value of $z$ is sufficiently high. We assume that the value of $z_{h}$ is sufficiently high so that high-productivity jobs are never severed. The worker and firm bargain efficiently over the terms of their relationship, and thus they make acceptance and continuation decisions that maximize their joint surplus. The joint surplus for a low-productivity job can be written as

$$
s_{l, t}(z)=\left(1-\tau_{e, t}(z)\right) z+g_{l, t}(z)-b_{l}+\left(1-\tau_{u, t}\left(r_{l}\right)\right) r_{l}-w_{l, t}^{w}-w_{l, t}^{f}
$$

for $z$ equal to $z_{l, 1}$ and $z_{l, 2}$. Here $\tau_{e, t}(x)$ is the tax rate on productive income equal to $x$ in period $t$ and $\tau_{u, t}(x)$ is the tax rate on unemployment benefits equal to $x, g_{l, t}(z)$ denotes the future joint value from continuing the relationship when the current productivity level is equal to $z, w_{l, t}^{w}$ denotes the low-productivity worker's discounted future benefits from entering the unemployment pool in the current period, and $w_{l, t}^{f}$ denotes the low-productivity entrepreneur's discounted future benefits from entering the matching market in the current period. The functions $s_{l, t}(z), \tau_{e, t}(z), \tau_{u, t}(b)$, $w_{l, t}^{f}, w_{h, t}^{f}, w_{l, t}^{w}$, and $w_{h, t}^{w}$ are indexed by $t$ to indicate their dependence on the current and expected future distribution of agents over the different employment and unemployment categories. ${ }^{10}$

In equilibrium, $s_{l, t}(z)$ is an increasing function of $z,{ }^{11}$ and there exists a cutoff level, $\underline{z}_{l, t}$, such that relationships with a value of $z$ bigger than or equal to $\underline{z}_{l, t}$ have a non-negative surplus and, thus, continue the relationship, while relationships with a value of $z$ less than $\underline{z}_{l, t}$ have a negative surplus and break up. The cutoff level is

\footnotetext{
${ }^{9} \mathrm{~A}$ fraction $\phi$ of all new borns have low-productivity skills.

${ }^{10}$ To be precise, the variables $s_{l, t}(z), w_{l, t}^{f}, w_{h, t}^{f}, w_{l, t}^{w}$, and $w_{h, t}^{w}$ only depend on current and future tax rates but depend on characteristics of the cross-sectional distribution because $\tau_{e, t}(z)$ and $\tau_{u, t}(b)$ do.

${ }^{11}$ At least when the tax policy is such that $\left(1-\tau_{e}(z)\right) z$ is increasing in $z$.
} 
the level of $z$ at which the surplus inclusive of destruction costs, $s_{l, t}(z)$, is equal to zero. Thus,

$$
s_{l, t}\left(\underline{z}_{l, t}\right)=0 .
$$

If there are no costs to destroy or create a match, the cutoff level for newly matched relationships is also equal to $\underline{z}_{l, t}$. Analogous equations can be written down for the cutoff level for high-productivity relationships, $\underline{z}_{h, t}$, but these are not that interesting since we assume that $z_{h}$ is always bigger than $\underline{z}_{h, t}$.

\subsection{Fiscal Policy}

Throughout the paper we assume that tax rates on productive income are equal for all agents (that is, $\tau_{e, t}(z)=\tau_{t}$ ), and that the tax rate on unemployment benefits is equal to $\psi \tau_{t}$, where $\psi$ has a value less than one to capture the empirical fact that tax rates on benefits are lower than those on productive income. ${ }^{12}$ We will consider two opposite extreme cases on how the government chooses debt and tax rates to finance unemployment benefits. Under the first policy the government only uses current tax revenues to finance unemployment benefits, which means that the government's budget is balanced period by period. In this case, tax rates are solved from

$$
\tau_{t}\left[\sum_{j=1}^{2} z_{l, j} e_{l, j, t}+z_{h} e_{h, t}\right]=g o v+\left(1-\psi \tau_{t}\right)\left[r_{l} u_{l, t}+r_{h} u_{h, t}\right],
$$

where gov is the level of per capital government expenditures which is assumed fixed, $e_{l, j, t}$ denotes the mass of employed workers with productivity level $z_{l, j}, j \in\{1,2\}$ in period $t, e_{h, t}$ denotes the mass of employed high-productivity workers, $u_{l, t}$ denotes the mass of low-skilled unemployed workers, and $u_{h, t}$ denotes the mass of high-skilled unemployed workers. We will refer to this policy as the balanced-budget fiscal policy. We also consider the fiscal policy where the government sets a constant tax rate, $\tau_{t}=\tau$, such that the present value of current and future tax revenues is equal to the present value of current and future transfers to the unemployed plus the amount of outstanding government debt. That is,

$$
\begin{gathered}
\tau\left[\sum_{k=0}^{\infty} \sum_{j=1}^{2} \beta^{t+k-1}\left[z_{l, j} e_{l, j, t+k}+z_{h} e_{h, t+k}\right]\right]= \\
d_{t}+\sum_{k=0}^{\infty} \beta^{t+k-1}\left[\text { gov }+(1-\psi \tau)\left(r_{l} u_{l, t+k}+r_{h} u_{h, t+k}\right)\right],
\end{gathered}
$$

where $d_{t}$ is the amount of outstanding government debt at the beginning of period $t$. We will refer to this policy as the balanced-NPV policy. Under both the balancedbudget and the balanced-NPV policy, the government sets tax rates taking the level

\footnotetext{
${ }^{12}$ See Section 5 below.
} 
of unemployment benefits and government expenditures as well as the expectations of the agents as given and we will, therefore, refer to these as passive policies. We will compare those with a fiscal policy in which the government commits to a sequence of tax rates. Under this policy the government expenditures will adjust, if necessary, to satisfy 4 . We will refer to this fiscal policy as the fiscal policy with credible commitment.

\subsection{Equilibrium}

In this section we discuss equilibrium values for $g_{l, t}(z), g_{h, t}, w_{l, t}^{w}, w_{h, t}^{w}, w_{l, t}^{f}, w_{h, t}^{f}$, and steady-state conditions for the distribution over the different employment and productivity categories. The joint value from continuing a low-productivity relationship is equal to

$$
g_{l, t}(z)=\beta\left(1-\rho^{r}\right)\left[\begin{array}{c}
\left(1-\rho^{x}\right)\left\{\sum_{j=1}^{2} s_{l, t+1}\left(z_{l, j}\right) I_{\underline{z}_{l, t+1}}\left(z_{j}\right) p\left(z_{j} \mid z\right)\right\}+ \\
b_{l}+\left(1-\psi \tau_{t+1}\right) r_{l}+w_{l, t+1}^{w}+w_{l, t+1}^{f}
\end{array}\right]
$$

for $z$ equal to $z_{l, 1}$ and $z_{l, 2}$. Here $I_{\underline{z}_{l, t}}(z)$ is an indicator function with a value equal to 1 if $z \geq \underline{z}_{l, t}$ and a value equal to 0 otherwise. Similarly,

$$
g_{h, t}=\beta\left(1-\rho^{r}\right)\left[\begin{array}{c}
\left(1-\rho^{x}\right) s_{h, t+1}\left(z_{h}\right)+ \\
b_{h}+\left(1-\psi \tau_{t+1}\right) r_{h}+w_{h, t+1}^{w}+w_{h, t+1}^{f}
\end{array}\right] .
$$

The continuation values for low-productivity workers and entrepreneurs with lowproductivity projects leaving the current period in the matching market satisfy

$$
\begin{aligned}
& w_{l, t}^{w}=\beta\left(1-\rho^{r}\right)\left[\begin{array}{c}
\lambda_{l}\left\{\sum_{j=1}^{2} \pi s_{l, t+1}\left(z_{l, j}\right) I_{\underline{z}_{l, t+1}}\left(z_{l, j}\right) p^{n}\left(z_{l, j}\right)\right\} \\
+b_{l}+\left(1-\psi \tau_{t+1}\right) r_{l}+w_{l, t+1}^{w}
\end{array}\right] \text { and } \\
& w_{l, t}^{f}=\beta\left(1-\rho^{r}\right)\left[\lambda_{l}\left\{\sum_{j=1}^{2}(1-\pi) s_{l, t+1}\left(z_{l, j}\right) \underline{I}_{\underline{z}_{t+1}}\left(z_{l, j}\right) p^{n}\left(z_{l, j}\right)\right\}+w_{l, t+1}^{f}\right] .
\end{aligned}
$$

Similarly, the continuation values for the high-productivity workers and entrepreneurs are equal to

$$
\begin{gathered}
w_{h, t}^{w}=\beta\left(1-\rho^{r}\right)\left[\lambda_{h} \pi s_{h, t+1}\left(z_{h}\right)+b_{h}+\left(1-\psi \tau_{t+1}\right) r_{h}+w_{h, t+1}^{w}\right], \\
w_{h, t}^{f}=\beta\left(1-\rho^{r}\right)\left[\left\{\lambda_{h}\left\{(1-\pi) s_{h, t+1}\left(z_{h}\right)\right\}+w_{h, t+1}^{f}\right\}\right] .
\end{gathered}
$$

Here $\pi$ is the bargaining weight of the worker and $\lambda_{l}$ and $\lambda_{h}$ are the matching probabilities for the low-productivity and the high-productivity workers (and entrepreneurs) respectively. 
The equations determining the law of motion of the unemployment rate and distribution over the different productivity levels are straightforward but somewhat tedious. We, therefore, only give the equations to determine steady-state levels. The following five equations can be used to solve for the steady-state values of $u_{l}, u_{h}$, $e_{l, 1}, e_{l, 2}$, and $e_{h}$. An equal flow of workers into and out of the matching markets for low-productivity workers requires

$$
\begin{gathered}
\phi \rho^{r}+\left(1-\rho^{r}\right) \rho^{x}\left(e_{l, 1}+e_{l, 2}\right)+ \\
\left(1-\rho^{r}\right)\left(1-\rho^{x}\right) \sum_{i=1}^{2} \sum_{j=1}^{2}\left(1-I_{\underline{z}_{l}}\left(z_{l, j}\right)\right) p\left(z_{l, j} \mid z_{l, i}\right) e_{l, i}= \\
{\left[\rho^{r}+\left(1-\rho^{r}\right) \lambda_{l} \sum_{j=1}^{2} I_{\underline{z}_{l}}\left(z_{l, j}\right) p^{n}\left(z_{l, j}\right)\right] u_{l} .}
\end{gathered}
$$

An equal flow into and out of the matching market for high-productivity workers requires

$$
(1-\phi) \rho^{r}+\left(1-\rho^{r}\right) \rho^{x} e_{h}=\left[\rho^{r}+\left(1-\rho^{r}\right) \lambda_{h}\right] u_{h}
$$

An equal flow of workers into and out of relationships with productivity level $z_{l, 1}$ requires

$$
\begin{gathered}
\left(1-\rho^{r}\right) \lambda_{l} I_{\underline{z}_{l}}\left(z_{l, 1}\right) p^{n}\left(z_{l, 1}\right) u_{l}+\left(1-\rho^{r}\right)\left(1-\rho^{x}\right) I_{\underline{z}_{l}}\left(z_{l, 1}\right) p\left(z_{l, 1} \mid z_{l, 2}\right) e_{l, 2}= \\
{\left[\rho^{r}+\left(1-\rho^{r}\right) \rho^{x}+\left(1-\rho^{r}\right)\left(1-\rho^{x}\right) p\left(z_{l, 2} \mid z_{l, 1}\right)\right] e_{l, 1}}
\end{gathered}
$$

An equal flow of workers into and out of relationships with productivity level $z_{l, 2}$ requires

$$
\begin{gathered}
\left(1-\rho^{r}\right) \lambda_{l} I_{\underline{z}_{l}}\left(z_{l, 2}\right) p^{n}\left(z_{l, 2}\right) u_{l}+\left(1-\rho^{r}\right)\left(1-\rho^{x}\right) I_{\underline{z}_{l}}\left(z_{l, 2}\right) p\left(z_{l, 2} \mid z_{l, 1}\right) e_{l, 1}= \\
{\left[\rho^{r}+\left(1-\rho^{r}\right) \rho^{x}+\left(1-\rho^{r}\right)\left(1-\rho^{x}\right) p\left(z_{l, 1} \mid z_{l, 2}\right)\right] e_{l, 2}}
\end{gathered}
$$

Finally an equal flow of workers into and out of relationships with productivity level $z_{h}$ requires

$$
\left(1-\rho^{r}\right) \lambda_{h} u_{h}=\left[\rho^{r}+\left(1-\rho^{r}\right) \rho^{x}\right] e_{h}
$$

\subsection{Extension}

In this section we introduce destruction and creation costs. Of course there is an empirical motivation to include these costs; creation of a new job obviously requires some setup costs and in Europe there are nontrivial costs associated with the elimination of positions. If these costs are substantial then it seems like a bad idea to ignore them in a paper that focuses on transitions between steady states. For example, in a steady state destruction costs are not important but during the transition from the low-unemployment steady state to the high-unemployment steady state they obviously are important. Similarly, during the transition out of the 
high-unemployment equilibrium creation costs play a crucial role. In the presence of these types of costs the surplus of a continuing match, $s^{o}(z)$, differs from the surplus of a newly created match, $s^{n}(z)$. In particular,

$$
s_{l, t}^{o}(z)=\left(1-\tau_{t}\right) z+g_{l, t}(z)-b_{l}+\left(1-\psi \tau_{t}\right) r_{l}-w_{l, t}^{w}-w_{l, t}^{f}+\zeta^{d e s},
$$

where $\zeta^{\text {des }}$ stands for the destruction costs. Similarly,

$$
s_{l, t}^{n}(z)=\left(1-\tau_{t}\right) z+g_{l, t}(z)-b_{l}+\left(1-\psi \tau_{t}\right) r_{l}-w_{l, t}^{w}-w_{l, t}^{f}-\zeta^{c r e},
$$

where $\zeta^{\text {cre }}$ stands for the creation costs.

\section{Steady states}

In Section 3.1, we discuss the properties of the two steady states. In Section 3.2, we address whether a change in agents' expectations without an accompanying change in a fundamental variable can drive the economy out of a steady state. We will find that this may depend on the type of fiscal policy implemented. ${ }^{13}$ If a change in expectations by itself cannot drive the economy out of the steady state then we say that staying in the steady state is the unique continuation equilibrium. In the first two subsections fiscal policy is passive and the government takes the expectations of the private sector as given when it sets tax rates. In Section 3.3 we consider a tax policy where the government moves first and commits to a particular tax rate.

\subsection{Properties of the two steady states}

Table 1 reports the three sets of parameter values used in the numerical examples. To understand the discussion below note that we always assume that all newly created low-productivity matches start at $z_{1}$, that is, $p^{n}\left(z_{2}\right)=0$. Motivation for this choice and other key parameter values will be given below. Also, for all three sets of parameter values, we keep the parameters that determine steady-state values of the tax rates and unemployment rates the same. In particular, the two steady states always have the following properties. In both the low-unemployment and the high-unemployment steady state there is some unemployment due to the entrance of new workers and exogenous job destruction. In the low-unemployment regime this is the only source of unemployment. In the high-unemployment regime the

\footnotetext{
${ }^{13}$ That is, this model does not satisfy Ricardian Equivalence. This is not surprising given that productive income is taxed at a different rate than unemployment benefits and the non-monetary benefit of unemployment is not taxed at all.
} 
low-productivity jobs have a negative surplus so no low-productivity workers are employed. For the low-unemployment regime to be an equilibrium it is necessary that the surplus of all relationships be positive. For the high-unemployment regime to be an equilibrium it is sufficient that the surplus of newly created low-productivity relationships, i.e., $s_{l}\left(z_{l, 1}\right)$ is negative (and the surplus of the high productivity relationships is positive). It is easy to find parameter values such that the model has these two steady-state equilibria. Table 2 documents the unemployment rates and tax rates for the example used in this paper. The unemployment rates are equal to $4.7 \%$ and $13.5 \%$ in the low-unemployment and high-unemployment steady state, respectively. This substantial increase in the unemployment rate corresponds to an increase in the tax rate from 29.9 to 35.5 per cent. An increase in the tax rate of 5.6 percentage points, while not humongous, is high enough to drive the marginal jobs out of existence. There are two reasons for this increase in the tax rate. The first is an increase in total transfers to the unemployed, which is responsible for roughly 3.8 percentage points. But even if total transfers would have remained the same there would have been an increase in the tax rate since total productive income has been reduced, so a higher tax rate is needed for the same amount of government expenditures.

\subsection{Unique continuation equilibrium}

In this section we address the question of whether the steady-state equilibria described above are unique continuation equilibria. We start in section 3.2.1 by discussing the properties of the model that affect the answer to this question. Particularly important is fiscal policy, and in section 3.2.2 we discuss in more detail whether staying in the steady state is the unique continuation equilibrium under passive fiscal policies.

\subsubsection{Properties that affect uniqueness of equilibrium}

This section will focus on examples in which staying in the steady state is a unique continuation equilibrium under at least one type of passive fiscal policy. It might, therefore, be worthwhile to point out that it is also possible to construct examples in which staying in the steady states is not a unique continuation equilibrium under either fiscal policy. This is easier to do for the low than for the high-unemployment steady state, since the destruction of jobs is instantaneous but the creation of jobs takes time. Suppose that the parameter values are such that the surplus values at both low-productivity levels are negative in the high-unemployment regime and positive in the low-unemployment regime. In this case the low-unemployment steady 
state is not the unique continuation equilibrium. To see why, suppose the system is in the low-unemployment steady state, but all agents expect to move to the high-unemployment steady state. Then all low-productivity relationships will break up in the current period and the system will switch instantaneously to the highunemployment steady state.

There are several ways one can construct examples in which expectations by themselves cannot force the system out of the existing steady state. To rule out the instantaneous shift to the high-unemployment steady state described above, we assume an upward drift in productivity values. In particular, it is assumed that all newly matched low-productivity relationships start at the lowest productivity level, $z_{l, 1}$. Having an upward drift is desirable in itself since Den Haan, Ramey, and Watson (2000b) show that models with an upward drift in productivity can replicate observed data on wages of displaced workers while models with a downward drift or no drift cannot.

This assumption is important for considering whether staying in the steady state is the unique continuation equilibrium. In the low-unemployment regime, the endogenous destruction and rejection rates are zero, which means that the tax rates are low, which in turn implies that the surpluses at all three productivity levels are positive. In our upward-drift example, with $z_{l, 1}<z_{l, 2}$, the parameter values are such that that $s_{l}\left(z_{l, 1}\right)<0<s_{l}\left(z_{l, 2}\right)$ in the high-unemployment steady state. Although $s_{l}\left(z_{l, 2}\right)>0$, no jobs will operate at $z=z_{l, 2}$ in the high-unemployment steady state since all low-productivity pairs have to start at $z_{l, 1}$ and these jobs are not created. Now suppose that the economy is in the low-unemployment steady state and agents expect to be moving towards the high-unemployment steady state. Even when the high-unemployment steady-state has been reached the surplus at $z_{l, 2}$ is positive, so the expectation the economy will move to the high-unemployment steady state will not make $s_{l}\left(z_{l, 2}\right)$ negative and relationships with a productivity level equal to $z_{l, 2}$ will, thus, not choose to break up. This means that the convergence towards the high-unemployment steady state will be slow. The slow convergence implies a slow increase in the unemployment rate and if the corresponding increase in the tax burden is not severe enough then $s_{l}\left(z_{1}\right)$ will-at least initially-remain positive, which is inconsistent with the agents' expectations that the economy is moving towards a high-unemployment steady state.

This example hopefully also makes clear that fiscal policy and the discount rate are also important for considering whether staying in the steady state is the unique continuation equilibrium. For example, if the discount factor is relatively high, then the belief that the economy is going downhill will lead to a larger decrease in the continuation value of staying in a relationship and, thus, to a larger drop in the surplus. In the next subsection we discuss fiscal policy in more detail. Finally, by 
introducing destruction costs or creation costs it becomes more likely that staying in the steady state is the unique continuation equilibrium.

\subsubsection{Uniqueness under alternative passive fiscal policies}

A steady state is more likely to be the unique continuation equilibrium under the balanced-fiscal policy than under the NPV-balanced fiscal policy. The reason is that if the government implements a balanced-NPV fiscal policy then it sets tax rates according to the expectations of the private sector, thereby reinforcing these expectations. The difference between the two fiscal policies becomes clear if we look at the implied tax rates if agents believe the economy will move out of the highunemployment steady state towards the low-unemployment steady state. The time paths for tax rates under the two policies are plotted in Figure 1 for the parameter set with the low discount rate and no destruction or creation costs. Because of the matching friction, unemployment rates decline slowly, which under a balancedbudget fiscal policy translates into tax rates that decrease slowly. In fact, just after the transition the tax rates are still so high that the surplus of newly created matches is still negative. ${ }^{14}$ Under the NPV-balanced fiscal policy, the government sets the tax rate such that the present value of tax revenues equals the present value of government expenditures where both are calculated using the beliefs of the private sector. This implies an immediate and substantial reduction in the tax rate from $29.1 \%$ to $24.5 \%$. Since the unemployment rate hasn't gone down yet this also implies an increase in the government's budget deficit. But it is worth it because under this fiscal policy, moving to the low-unemployment steady state is an equilibrium. ${ }^{15}$

We will now discuss in more detail how to check whether a steady state is a unique continuation equilibrium. For a steady state to be an equilibrium you need that the sign of the surplus is consistent with the creation and destruction decision used to construct the steady state. For example, the high-unemployment steady state requires that the surplus of newly created low-productivity matches, $s_{l}\left(z_{l, 1}\right)<0$, so that indeed no low-productive matches are operating. Suppose that at $t=0$ the economy is in the high-unemployment steady state. If there is an equilibrium time path for which the economy does not stay in the high-unemployment steady state, then it must be the case that in period $t=1$ the surplus of newly created low-productivity matches, $s_{l, 1}\left(z_{l, 1}\right) \geq 0$. Showing that staying in a steady state is a

\footnotetext{
${ }^{14}$ This is the reason why staying in the steady state is the unique continuation equilibrium under the balanced-budget fiscal policy.

${ }^{15}$ It is important to point out that even under the balanced-budget fiscal policy, future tax decreases are taken into account in the agents' decisions through their impact on the continuation values $g_{l, t}, g_{h, t}, w_{l, t}^{f}, w_{h, t}^{f}, w_{l, t}^{w}$, and $w_{h, t}^{w}$.
} 
unique equilibrium might seem a daunting task because there are so many alternative time paths to consider. The time path that is most likely to make $s_{l, 1}\left(z_{l, 1}\right) \geq 0$, however, is the time path for which at every point in time newly matched pairs create a productive relationship and no relationships choose to break up, that is, the time path that converges directly to the low-unemployment steady state and stays there. This is the time path that will lead to the largest possible reduction in unemployment benefits and tax burden and, thus, the largest increase in the surplus values.

It is not difficult to check whether this alternative time path is an equilibrium. The assumption that all matches lead to productive relationships and no relationships choose to break up imply a time path for the unemployment rate, output, and the government's obligations to pay unemployment benefits. Under the balancedbudget fiscal policy these imply a time path for the tax rates. Since the economy moves to the low-unemployment steady state, the limiting continuation values under the alternative time path are equal to the low-unemployment steady-state values. One can then solve for the time path of the continuation values by assuming they have attained the steady-state values for a large value of $t$ and then iterate backwards using Equations 5 through 10. Next we calculate the time path for the surplus values and if $s_{l, t}\left(z_{l, 1}\right) \geq 0$ for all $t$ then the alternative time path is also an equilibrium and staying in the high-unemployment steady state is not a unique equilibrium. The procedure under the NPV-balanced fiscal policy is similar. The implied time path of the government's expenditures and output lead to a new constant tax rate. Since tax rate are constant along the transition path, continuation values and surplus values are constant too. Again, if the surplus value at the lowest productivity level is nonnegative then the alternative time path is an equilibrium under the NPV-balanced fiscal policy.

In the framework considered in this paper it is not trivial to construct examples in which (i) the discount factor is high, (ii) there are no destruction or creation costs, (iii) the government implements the NPV-balanced fiscal policy, and (iv) staying in the steady states is a unique continuation equilibrium. One might, therefore, be tempted to conclude that steady states that are unique continuation equilibria are implausible unless there are destruction or creation costs. Note, however, that under the alternative time path the economy moves to the other steady state and stays there forever. Since the transition is permanent the change in the tax burden is huge, which makes it more likely that moving out of the steady state is an equilibrium time path. In reality, this alternative time path may not be that realistic and one may want to rule them out in the model. ${ }^{16}$ This would make it more likely that the

\footnotetext{
${ }^{16}$ For example, by adding stochastic shocks to the model, which at some point will force the economy out of the alternative steady state.
} 
steady state is a unique continuation equilibrium.

For the parameter values in the first column of Table 1, the discount factor is low, $\beta=0.8$, there are no destruction or creation costs, and both steady state are unique continuation equilibria under both passive fiscal policies. In the second column the discount factor has a more realistic value, $\beta=0.98$, both steady states are unique continuation equilibria under the balanced-budget fiscal policy but not under the NPV-balanced fiscal policy. In the third column the discount factor has again a value equal to 0.98 and there are positive destruction and creation costs. Now both steady states are unique continuation equilibria again under both types of passive fiscal policy.

\subsection{Using fiscal policy to eliminate high unemployment}

In this subsection we first discuss how the government can use debt management to select the desirable equilibrium time path when staying in the high-unemployment steady state is not the unique time path. Next, we show that if we allow productive income to be taxed at different rates, then fiscal policy can be used to even eliminate the high-unemployment steady state.

\subsubsection{Debt management and selecting the desirable time path}

In the last subsection we showed that it is possible that staying in the high-unemployment steady state is not the unique continuation time path if the government implements an NPV-balanced fiscal policy. The question then arises whether the government can use its fiscal policy to select the equilibrium time path that converges to the lowunemployment equilibrium. In particular, suppose that the government announces that from now on the tax rate will be equal to the (constant) level corresponding to the time path along which the economy moves out of the high-unemployment steady state. At this tax rate the surplus values for all productivity levels are positive, and the government balances the present value of its revenues and expenditures. One might be tempted to conclude that by committing to this tax rate the government eliminates staying in the high-unemployment steady state as an equilibrium; the only remaining equilibrium is to move towards the low-unemployment steady state. Bassetto (2002) points out this establishes the uniqueness of an equilibrium but under the assumption that the private sector believes that the government will act in a way that is simply impossible under some scenarios. In particular, suppose that the private sector does not believe that the economy will converge towards the lowunemployment steady state. Under the assumption that the government commits to a low tax rate, the present value of government expenditures and revenues are 
no longer equal. It is unclear what would happen under this scenario. It is possible that the government would break its commitment. Since one cannot evaluate the alternatives, one also cannot conclude there is not an equilibrium among the alternatives. An easy way out of this problem is to assume that the government commits

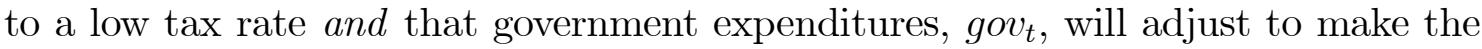
net-present-value of the government's budget deficits equal to zero. It is easy to see that with this modification the time path along which the economy moves to the low-unemployment steady state is the unique equilibrium. Note that in equilibrium the government doesn't have to adjust the level of government expenditures. It only has to do so along off-equilibrium time paths. ${ }^{17}$

The point made by Bassetto (2002) may very well have important practical implications. If the government "commits" to a time path of tax rates and government expenditures then it is hard to predict what will happen when the expectations of the private sector are such that even the NPV version of the government's budget constraint is not satisfied.

\subsubsection{Using fiscal policy to eliminate the high-unemployment steady state}

The discussion above makes clear that this model does not imply Ricardian Equivalence. The reason is that a decrease in the tax rate in the current period financed by an increase in a future tax rate may affect different people. For example, if you are in a productive relationship today you will benefit from the decrease in the current tax rate but you care less about the future tax increase because you may either be unemployed or retired. Similarly, the current unemployed benefit less from the current decrease in the tax rate, which means a reduction in the outside option relative to the benefits of staying within the productive relationship. In fact, if the disutility of working is equal to zero, i.e., $b_{l}=b_{h}=0$, then a simple way to eliminate the high-unemployment steady state is to make all tax rates equal to each other. In this case an increase in tax rate would not affect the values of the surplus and, thus, destruction and rejection rates would remain unchanged.

If the surplus of the high productivity relationships is high enough, then the highunemployment steady-state can be eliminated by a transfer of funds from the highproductivity relationships to the low-productivity relationships. ${ }^{18}$ That is, instead of transferring funds from the productive relationships to the unemployed there

\footnotetext{
${ }^{17}$ Note that we also could make unemployment benefits the residual in the government's fiscal policy.

${ }^{18}$ This could be in the form of letting the low-productivity relationships pay no or possibly less taxes.
} 
would be transfers from the more productive to the less productive workers. A sufficient condition for this to be a Pareto improvement is that $b_{l}<z_{l, 1}$, since in this case one has to transfer less than $r_{l}$. However, a policy like this one that subsidizes marginal jobs might not be politically feasible or desirable. First, it may be difficult to implement such a policy since what matters here is not the value of the output produced or profits but the value of the surplus. This may be hard for the government to observe, that is, one may be taxing firms with a high level of revenues or profits but low surplus. Moreover, keeping marginal jobs alive may not always be desirable in the long run. In this model, the fraction of high-productivity workers is fixed at $\phi$ but it may very well respond to market conditions. In this case, the value of $\phi$ would increase over time if the economy suffers from high-unemployment, for example, because education increases. The economy might eventually end up in a low-unemployment regime but one with a higher fraction of high-productivity workers.

\section{$4 \quad$ Small and large temporary shocks}

In this section we discuss how the economy can move out of a steady state in response to temporary shocks. In the first subsection we discuss shocks when the economy is in the low-unemployment steady state to begin with and in the second subsection the economy starts in the high-unemployment steady state.

\subsection{Transitions out of the low-unemployment steady state}

The aggregate fundamental shock considered here is a one-time change in the rate of exogenous break ups. Although we think of this burst of destruction as being caused by a one-time drop in productivity we don't actually change productivity levels which simplifies the exposition. Note, however, that by keeping productivity levels the same it is easier to remain in the low-unemployment steady state.

\subsubsection{Small shocks}

If the low-unemployment steady state is a unique continuation equilibrium then the economy will converge back towards the low-unemployment steady state after a small enough burst of destructions. This small shock will lead to an increased obligation of the government to pay unemployment benefits and necessarily leads to an increase in tax rates at some point but the economy should be able to withstand small enough shocks if the staying in the low-unemployment steady state is a unique 
continuation equilibrium. ${ }^{19}$

\subsubsection{Large shocks}

Clearly there are shocks large enough such that the economy will leave the lowunemployment steady state. In particular, suppose that there is a one-time sharp reduction in the productivity level of the low-productivity relationships that is so large that the values of the surplus of these relationships become negative. This means that these relationships break up and the economy reaches the high-unemployment steady state instantaneously. Since the high-unemployment steady state is a unique continuation equilibrium, the belief that the economy will converge back to the lowunemployment steady state is not going to prevent the economy from slipping to this high-unemployment steady state. Moreover, because the high-unemployment steady state is a unique continuation equilibrium, shocks that lead to unemployment rates close to the level of the high-unemployment regime cause an inevitable transition to the high-unemployment steady state.

\subsubsection{Intermediate shocks}

Above we showed that if the shock is small enough the unique equilibrium is to move back to the low-unemployment steady state, while if the shock is large enough the economy has to move to the high-unemployment steady state. Not surprisingly, there are intermediate shocks for which expectations are not uniquely determined and the economy could either move back towards the low-unemployment steady state or move towards the high-unemployment steady state. In Figure 2 we have plotted the possible time paths for the unemployment rate after a burst of destruction. The solid line represents the unemployment rate after the largest possible burst of destruction after which return to the low-unemployment steady state is still an equilibrium under the balanced-budget fiscal policy. In particular, if the burst of destruction leads to an unemployment rate equal to $10.5 \%$ or less then the economy can still move back to the low-unemployment regime. ${ }^{20}$ If the initial unemployment rate is larger than $10.5 \%$ then the economy will have to move to the high-unemployment regime. The dashed line represents the unemployment rate after the smallest possible burst of destruction after which the economy could still move

\footnotetext{
${ }^{19}$ If staying in the low-unemployment steady state is a unique continuation equilibrium, then the belief that the economy will move out of the steady sate-without a change in any of the fundamentals-leads to a time path with $s_{l, t}\left(z_{l, 1}\right)>0$ at least for $t=1$. Continuity of $s_{l, t}\left(z_{l, 1}\right)$ then guarantees that $s_{l, t}\left(z_{l, 1}\right)$ remains positive in response to a small change in the fundamentals.

${ }^{20}$ The procedure to check whether a time path is an equilibrium is the same as the one used to check whether moving out of the steady state is an equilibrium.
} 
to the high-unemployment steady state under the same fiscal policy. In particular, if the initial unemployment rate is equal to $8.9 \%$ or more then the economy could move to the high-unemployment regime. If the initial unemployment rate is less than $8.9 \%$ the economy has to move back to the low-unemployment steady state. Thus, if the initial unemployment is between $8.9 \%$ and $10.5 \%$ then the economy could move to either steady state. It is important to note that these values are very sensitive to changes in parameters such as $b_{l}$. For example, if we would increase the value of $b_{l}$ then breakup becomes more likely and the initial unemployment rate for which the economy would have to move to the high-unemployment steady state would be less than $10.5 \%$.

When the government implements NPV-balanced fiscal policy then the range for which the time path is indeterminate is between $8.6 \%$ and $11.7 \%$. We see that the indeterminate region under this fiscal policy is slightly larger. This is not surprising since under this policy the government reinforces the agents' expectations. That is, if the agents' expect the economy to return to the low-unemployment steady state then the initial increase in tax rates will be bigger.

\subsection{Transitions out of the high-unemployment steady state}

Suppose the surplus of marginal jobs in the low-unemployment steady state, $s_{l}\left(z_{l, 1}\right)$, is slightly positive. Then a small temporary negative shock might force the economy to the high-unemployment steady state. If instead the surplus of marginal jobs in the high-unemployment steady states is only slightly negative then a small positive shock might push the economy to the low-unemployment equilibrium; the effect of temporary shocks in the two steady states doesn't have to be symmetric.

There is no reason, however, why the absolute value of $s_{l}\left(z_{l, 1}\right)$ would be higher in one of the steady states. Suppose, therefore that the absolute value of $s_{l}\left(z_{l, 1}\right)$ is similar in both steady states. There are still reasons why the effect of temporary shocks would not be symmetric. In particular, there are important reasons why one would expect it to be typically more difficult to move out of the highunemployment steady state than out of the low-unemployment steady state. The first reason is the obvious fact of life that destruction can be quick, but restoration unfortunately takes time. This asymmetry is amplified in this model by the effect of job destruction on tax rates. Since destruction is instantaneous and creation is not, the tax increase corresponding to a period of negative shocks is larger than the decrease corresponding to a period of positive shocks. Suppose the economy is in the low-unemployment steady state and that a large aggregate shock destroys all low-productivity relationships. Then the tax rate increases immediately from $29.9 \%$ to $35.5 \%$ for both fiscal policies. Now suppose that the economy is in the high- 
unemployment steady state and the government implements NPV-balanced fiscal policy. Consider the case where the rejection rate of all matched pairs is equal to zero so that the economy will converge to the low-unemployment steady state. Since the unemployment rate shrinks only gradually the tax rate decreases from $35.5 \%$ not to $29.9 \%$ but to $33.2 \%$ for the parameters in the first column of Table 1 and to and $30.7 \%$ for the parameters in the last two columns.

If productivity temporarily improves then only continuing relationships and newly matched pairs can benefit from this. If productivity is high for a long enough time period, then eventually the unemployment rate will have been reduced enough so that the economy can converge to the low-unemployment steady state even when productivity returns to its normal value. Suppose the government balances the budget period by period. After ten periods of positive shocks, during which all new matches become productive relationship, the unemployment rate has decreased enough so that the economy could converge to the low-unemployment steady state. ${ }^{21}$ If the government implements the balanced-NPV fiscal policy then the unemployment rate is already low enough after only one period.

\section{European unemployment puzzle}

In the first subsection we document the time series behavior of unemployment, public expenditures on unemployment compensation and labor market programs, tax rates, and replacement rates for several European countries and the United States. We argue that the analysis in the earlier sections can be used to explain the observed behavior of European unemployment rates. In the second subsection we argue that current European fiscal policies may sustain high unemployment rates.

\subsection{The role of taxes and unemployment benefits}

In this paper, we have incorporated a fairly standard model with multiple equilibria into a dynamic framework and shown that in this dynamic context the equilibrium time path may be uniquely determined by past realizations of the fundamental shock. That is, if the shocks were large enough then the unemployment rate has become so large that the transition to the other regime is unavoidable. This story fits the experience of European unemployment well. The idea is that Europe started in the low-unemployment steady-state in the 1950's and 1960's. Even though replacement rates were high, they did not result in high tax rates because the unemployment rate was low. The recession in the 1970's increased the government's obligation

\footnotetext{
${ }^{21}$ These numbers are for the parameter values in the third column of Table 1.
} 
to pay unemployment benefits. Because of the corresponding increase in the tax burden the economy could only converge towards the high-unemployment regime. The model predicts that along this time path to the high-unemployment regime tax rates should increase, both because of an increase in the amount of transfers to the unemployed and because of a decrease in aggregate productive income. We now show that this explains the data fairly well.

Standardized unemployment rates for Europe ${ }^{22}$ and the U.S. are plotted in Figure 3. As documented by the figure, the unemployment rates in Europe and the U.S. were low and fairly similar in the beginning of the sample. During the 1970's, European unemployment rates rose sharply and just when it seemed they might be leveling off they experienced another rapid increase from which they still haven't fully recovered. Unemployment rates in the U.S. in contrast, reached unemployment rates in the second half of the 1990's that were close to their all time lows.

The model in this paper shows that a large negative temporary shock can have a permanent effect on unemployment rates if it interacts with employment-unfriendly institutions. An important example of such an institution is the presence of high net replacement rates. In Table 3 we report net replacement rates for unemployed workers in several countries. The table documents that in most European countries net replacement rates are substantial relative to U.S. replacement rates. This gap cannot explain the high unemployment rates in Europe relative to the U.S., however, because European replacement rates were already high relative to U.S. levels at the beginning of the postwar period when unemployment rates were similar. ${ }^{23}$

The wedge between tax rates on productive income and unemployment benefits plays an important role in this paper. To illustrate the magnitude of this wedge we report in Table 4 average effective tax rates on labor income and unemployment benefits from Daveri and Tabellini (2000). The table shows that in all countries there are substantial differences in the effective tax rates. The tax rate on labor income averaged across European countries is equal to $35.8 \%$ while the average tax rate on unemployment benefits is equal to only $16.2 \%$. The findings in this table correspond roughly to our assumption that the tax rate on unemployment benefits is equal to four tenths of the tax rate on productive income. We calibrated the tax rate in the low-unemployment steady state to be equal to $30 \%$, which is the overall tax burden as a percentage of GDP over the period from 1966 to 1970 across European countries. ${ }^{24}$ This tax rate is in the range of observed effective labor tax rates for European countries.

In the first column of Table 5 we report the amount spent on unemployment

\footnotetext{
${ }^{22}$ The countries included are the fifteen members of the European Union.

${ }^{23}$ See, for example, Den Haan, Haefke, and Ramey (2002).

${ }^{24}$ See Table 7 below.
} 
benefits and in the second column total transfers to the working-age population, both as a percentage of GDP. The numbers on unemployment compensation in the first column of Table 5 should be considered as a lower bound on the total amount of income transfers paid because of labor market conditions to working-age individuals. One reason is that some unemployed are misclassified as sick or disabled ${ }^{25}$ and their compensation should be counted as part of the unemployment benefits paid out. The reported numbers on total transfers to the working-age population include government expenditures such as expenses on housing benefits, family benefits, and early retirement that benefit the unemployed and are also related to labor market conditions. Of course, they also include transfers to the truly sick and disabled that are not directly affected by market conditions.

Moreover, transfers are not the only government expenditures that are related to labor market conditions. Examples are expenditures on labor market training, subsidized employment public, and employment services and administration. The amount spent on these type of government programs is not necessarily small. ${ }^{26}$ For example, in 1995 Denmark spent 1.0 per cent of GDP on labor market training programs and 0.58 per cent of GDP on subsidized employment programs. Sweden spent in 1994-95 0.78 per cent of GDP on labor market training programmes and 0.90 per cent of GDP on subsidized employment.

These numbers suggest that it is not unreasonable to argue that the higher unemployment rates in Europe corresponds to labor-market-related transfers that, as a per cent of GDP, are at least several points higher than their U.S. equivalents.

Using only actual unemployment compensation transfers Saunders and Klau (1985) report how much the ratio of unemployment benefits to GDP has changed over the period from 1970 to 1981, which should be a good estimate of the change in total transfers from the low-unemployment period to the high-unemployment period. The results are reproduced in Table 6. The average increase of this ratio across European countries is equal to 4.51 percentage points. As documented in Table 2, the model is conservative in that it predicts an increase of 3.76 percentage points. Note that part of the observed increase is due to an increase in benefits levels ${ }^{27}$ and this is not taken into account in the model. To look at the implications for taxes we report in Table 7 the overall tax burden for the following three subperiods: 1966-1970, 1971-1975, and 1976-1982. Note that the tax rate generated by the model in the low-unemployment steady state closely matches the average tax burden for the sample period from 1966 to $1970 .{ }^{28}$ The increase in the tax burden

\footnotetext{
${ }^{25}$ See, for example, Nickell and van Ours (2000).

${ }^{26}$ See Table $\mathrm{T}$ in the statistical annex of OECD (1996).

${ }^{27}$ See Table 35 in Saunders and Klau (1985).

${ }^{28}$ This is accomplished by setting gov equal to 0.32 , which corresponds to a level of government
} 
predicted by the model of 5.6 percentage points covers a big part of the observed increase of 6.9 percentage points.

To assess the quantitative effects of tax rates on the economy, the following aspects are important to keep in mind. Creation of new jobs clearly plays an important role for the performance of an economy. That new jobs have a low surplus value seems very plausible. As demonstrated by the numerical examples above, relatively small changes in tax rates can have a big impact on the economy under these circumstances. Several other features that are not present in the model may aggravate the effect of tax rates. Note the matching process is the only friction in the model. For example, in this model there is always demand for the commodities supplied. ${ }^{29}$ The fact that demand for a new product (or an increase in supply) might be uncertain is an extra reason why the surplus level of new projects (or additional workers) may be very low. Also, because agents are assumed to be risk neutral there are no changes in the interest rate. Den Haan, Ramey, and Watson (2000a) show that fluctuations in the interest rate serve as an important magnification and propagation mechanism in a job matching model with capital. To see this, suppose a burst of destruction leads to a reduction in consumption. The desire to smooth consumption will increase interest rates. ${ }^{30}$ The increase in interest rates increases the cost of capital which in turn will increase the number of relationships destroyed. The desire to smooth consumption will lead to a reduction in the capital stock which in turn will put upward pressure on future interest rates and lead to more destruction in future periods. Finally, besides the externality associated with unemployment benefits and tax burdens, the presence of low-productivity relationships may generate other externalities in the economy. For example, the disappearance of service jobs like the home delivery of groceries would increase the costs of working and, thus, decrease the surplus of other jobs. Finally, if jobs remain unfilled for long periods of time networks affecting the efficiency of the matching market may deteriorate or disappear, which in turn may make it more difficult for these jobs to ever become productive again.

More empirical evidence for the view in this paper that the increase in total unemployment benefits paid out had a negative effect on economic activity can be found in Alesina, Ardagna, Perotti, and Schiantarelli (2002). Using an econometric panel analysis on a OECD panel data set, they document a sizable negative effect of public spending on business investment. In particular, they find that a one percentage point increase in transfers as a fraction of GDP decreases investment as a share of GDP- with $0.21 \%$ on impact and with a cumulative effect of $1.25 \%$

expenditures equal to $28 \%$ of GDP.

${ }^{29}$ Basically because agents eat their own production.

${ }^{30}$ Relative to what interest rates would do without the consumption-smoothing motive. 
over ten years.

\subsection{Current fiscal policy}

The model suggests that after a burst of destruction there are two possibilities. The first is that even if the government uses deficit management in an optimal way the economy will converge and stay in the high-unemployment regime unless the government conducts a complete overhaul of the transfer system, including subsidies to marginal jobs. Secondly, a commitment to low tax rates could prevent the economy from moving to the high-unemployment regime and instead force the economy back to the low-unemployment regime. In some cases, this policy could even work after the economy has reached the high-unemployment regime. To figure out which case is relevant for an actual economy would require some detailed research to determine the surplus values of new potential jobs. This may not be that easy since what really matters is the question how a reduction in tax rates affects those jobs that are under the current regime of high tax rates have a negative surplus and, thus, do not exist.

After the Maastricht Treaty, European governments have put a lot of emphasis on deficit reduction. This paper suggests that by doing so they may have given up a remedy against high unemployment rates. That is, by committing to an environment with low taxes the government could very well drive unemployment rates lower. Although this policy would lead to temporary increases in the budget deficit it would in the long run lead to a reduction in the government's transfers to the unemployed and an increase in the tax base. The analysis here as well as in Bassetto (2002) makes clear that under this policy the government has to be committed to the tax reduction, which means that taxes cannot be the residual instrument used to balance the budget. That is, true commitment requires a clear plan that describes which expenditures will be cut if the private sector is not convinced that the economy will converge towards the low-unemployment equilibrium.

\section{Concluding Comments}

In this paper we developed a dynamic framework with multiple steady states in which equilibrium selection is not controlled by the realization of a sunspot variable but in which time paths are determined by the realizations of past shocks. In the benchmark model we have the following results. After large temporary shocks the economy can only move to the high-unemployment equilibrium while after small shocks the economy can only move towards the low-unemployment equilibrium. Time paths are not always uniquely determined, however. For intermediate shocks, 
the economy could move either to the low or the high-unemployment equilibrium and expectations of the private sector would be self-fulfilling. The idea is that the unemployment rate, or more generally the implied tax burden, is a state variable that controls the solution to the model. In this aspect the model is similar to Den Haan, Ramey, and Watson (2002) in which large enough destructions to the network between entrepreneurs and financial intermediaries reduce the efficiency of the intermediation process to such an extent that the economy faces an unavoidable collapse.

Fiscal policy plays a key role in this paper and we have shown that fiscal policy can be used to (i) make the transition to the low-unemployment steady state an alternative equilibrium when moving to (or staying in) the high-steady state is an equilibrium time path if the government uses a NPV-balanced fiscal policy, and (ii) select transition to the low-unemployment steady state as the unique equilibrium if the government commits to low tax rates and is willing to adjust government expenditures under off-equilibrium time paths.

In spirit this paper this paper is similar to Daveri and Tabellini (2000) who also argue that an increase in tax rates play an important role in the increase in European unemployment rates. In Daveri and Tabellini (2000), however, the increase in tax rates is exogenous while here the increase is an endogenous response to temporary shocks. An interesting aspect of Daveri and Tabellini (2000) that is missing in this paper is the theoretical and empirical analysis that shows that the increase in tax rates not only affects unemployment rates but also growth rates. It would be interesting to extend the framework here and to model the effect of tax rates on growth rates along the lines used in, for example, Daveri and Tabellini (2000) or Novales and Ruiz (2002). This would not only increase the range of predictions made

by the model but can also magnify the effects of temporary shocks by including the effect of tax rates on real activity through economic growth.

\section{References}

[1] Alesina, A., S. Ardagna, R. Perotti, and F. Schiantarelli (2002), Fiscal Policy, Profits, and Investment, American Economic Review, 92, 571-589.

[2] Bassetto, M. (2002), Equilibrium and Government Commitment, Federal Reserve Bank of Minneapolis working paper \#624.

[3] Bryant, J. (1983), A Simple Rational-Expectations Keynes-Type Model, Quarterly Journal of Economics 98, 525-528. 
[4] Cooper, R., and D. Corbae (1997), Financial Fragility and the Great Depression, Journal of Economic Theory, forthcoming.

[5] Daveri, F., and G. Tabellini (2000), Unemployment, Growth and Taxation in Industrial Countries, Economic Policy, 15, April, 47-104.

[6] Den Haan, W.J., G. Ramey, and J. Watson (2000a), Job Destruction and Propagation of Shocks, American Economic Review, 90, June, 482-498.

[7] Den Haan, W.J., G. Ramey, and J. Watson (2000b), Job Destruction and the Experiences of Displaced Workers, Carnegie-Rochester Conference Series on Public Policy, 52, June, 87-128.

[8] Den Haan, W.J., G. Ramey and J. Watson (2002), Liquidity Flows and the Fragility of Business Enterprises, Journal of Monetary Economics, forthcoming.

[9] Den Haan, W.J., C. Haefke, and G. Ramey (2002), Shocks and Institutions in a Job Matching Model, NBER working paper \#8463.

[10] Farmer, R.E.A. (1997), Money in a Real Business Cycle Model, Journal of Money Credit and Banking, 29, 568-611

[11] Hornstein, A., P. Krusell, and G. Violante (2000), Technology, Policy, and the Inequality-Unemployment Tradeoff, manuscript.

[12] Lindbeck, A. (1996), The West European Employment Problem, Institute for International Economic Studies reprint series \#563, Stockholm University.

[13] Ljungqvist, L., and T.J. Sargent (1998), The European Unemployment Dilemma, Journal of Political Economy, 106, June, 514-550.

[14] Marimon, R., and F. Zilibotti (1999), Unemployment vs. Mismatch of Talents: Reconsidering Unemployment Benefits, Economic Journal, 109, April, 266-291.

[15] Mortensen, D.T., and C.A. Pissarides (1994), Job Creation and Job Destruction in the Theory of Unemployment, Review of Economic Studies, 61, July, 397-415.

[16] Mortensen, D.T., and C.A. Pissarides (1999), Unemployment Responses to 'Skill-Biased' Technology Shocks: the Role of Labour Market Policy, Economic Journal, 109, April, 242-265.

[17] Nickell, S., and J. van Ours (2000), The Netherlands and the United Kingdom: A European unemployment miracle? Economic Policy, 30, 135, 137-180. 
[18] Macfarlan, M., and H. Oxley (1996), Social Transfers: Spending Patterns, Institutional Arrangements and Policy Responses, OECD Economic Studies, 27, 147-194.

[19] Martin, J.P. (1996), Measures of Replacement Rates for the Purpose of International Comparisons: A Note, OECD Economic Studies, 26, 99-116.

[20] Morris, S, and H.S. Shin (2000), Rethinking Multiple Equilibria in Macroeconomic Modelling, NBER Macroeconomics Annual, 2000, 139-161.

[21] Novales, A., and J. Ruiz (2002), Dynamic Laffer Curves, Journal of Economic Dynamics and Control," 27, 181-206.

[22] OECD (1996), Employment outlook, OECD, Paris.

[23] Saunders, P., and F. Klau (1985), The Role of the Public Sector, OECD Economic Studies 4, 4-239. 
Table 1: Parameter Values

\begin{tabular}{lccc}
\hline & $\begin{array}{c}\text { low discount } \\
\text { factor }\end{array}$ & \multicolumn{2}{c}{$\begin{array}{c}\text { high discount } \\
\text { factor }\end{array}$} \\
\hline$\zeta^{\text {cre }}=\zeta^{\text {des }}=\mathbf{0}$ & $\boldsymbol{\zeta}^{\text {cre }}=\boldsymbol{\zeta}^{\text {des }}=\mathbf{0}$ & $\boldsymbol{\zeta}^{\text {cre }}$ & $\boldsymbol{\zeta}^{\text {des }}>\mathbf{0}$ \\
\hline$\beta$ & 0.8 & 0.98 & 0.98 \\
$\zeta^{\text {cre }}$ & 0 & 0 & 0.30 \\
$\zeta^{\text {des }}$ & 0 & 0 & 0.55 \\
$b_{l}=b_{h}$ & 0.2425 & 0.2620 & 0.2550 \\
$r_{l}=r_{h}$ & .5 & $=$ & $=$ \\
$z_{l, 1}$ & 1.00 & $=$ & $=$ \\
$z_{l, 2}$ & 1.065 & $=$ & $=$ \\
$z_{h}$ & 1.2 & $=$ & $=$ \\
$\rho^{x}$ & 0.01 & $=$ & $=$ \\
$\rho^{r}$ & 0.01 & $=$ & $=$ \\
$p^{n}\left(z_{l, 1}\right)$ & 1 & $=$ & $=$ \\
$p\left(z_{l, 2} \mid z_{l, 1}\right)$ & 0.4 & $=$ & $=$ \\
$p\left(z_{l, 1} \mid z_{l, 2}\right)$ & 0 & $=$ & $=$ \\
$\lambda_{l}$ & 0.1 & $=$ & $=$ \\
$\lambda_{h}$ & 0.5 & $=$ & $=$ \\
$\phi$ & 0.9 & $=$ & $=$ \\
$\psi$ & 0.4 & $=$ & $=$ \\
$g o v$ & 0.32 & & $=$ \\
\hline
\end{tabular}

Note: An equality sign in this table indicates that the parameter has a value equal to the value reported in the first column.

Table 2: Steady-state properties

\begin{tabular}{lcc}
\hline & $\begin{array}{c}\text { low-unemployment } \\
\text { steady state }\end{array}$ & $\begin{array}{c}\text { high- } \\
\text { unemployment } \\
\text { steady state }\end{array}$ \\
\hline unemployment rate & $4.7 \%$ & $13.5 \%$ \\
tax rate & $29.9 \%$ & $35.5 \%$ \\
total transfers / output & $1.81 \%$ & $5.57 \%$ \\
\hline
\end{tabular}


Table 3: 1994/1995 Net replacement rates

\begin{tabular}{lc}
\hline Country & $\begin{array}{c}\text { Net Replacement } \\
\text { Rate }\end{array}$ \\
\hline Belgium & 59 \\
Denmark & 81 \\
Italy & 19 \\
Netherlands & 69 \\
Norway & 62 \\
Spain & 49 \\
Sweden & 67 \\
U.K. & 51 \\
U.S. & 16 \\
\hline
\end{tabular}

Note: The numbers are from Table 2 in Martin (1996) and represent an overall average across beneficiaries with different family circumstances for the first five years of unemployment. They are expressed as a percentage of the pre-displacement wage.

Table 4: Effective tax rates on labor income and unemployment benefits (1961-91 average)

\begin{tabular}{lccc}
\hline Country & $\begin{array}{c}\text { labor } \\
\text { income }\end{array}$ & $\begin{array}{c}\text { unemployment } \\
\text { subsidies }\end{array}$ & difference \\
\hline Belgium & 39.2 & 27.3 & 11.9 \\
France & 39.8 & 31.0 & 8.8 \\
Germany & 36.3 & 8.0 & 28.3 \\
Italy & 34.0 & -4.4 & 38.4 \\
Netherlands & 44.6 & 29.7 & 14.9 \\
Norway & 37.0 & 20.8 & 16.2 \\
Spain & 24.8 & 16.2 & 8.6 \\
Sweden & 42.2 & 15.8 & 26.4 \\
U.K. & 24.2 & 1.2 & 22.9 \\
Europe (average) & 35.8 & 16.2 & 18.0 \\
U.S. & 24.1 & 0.8 & 23.3 \\
\hline
\end{tabular}

Note: These numbers are from Table 3 in Daveri and Tabellini (2000). 
Table 5: Transfers for the working-age population in 1992

\begin{tabular}{lcc}
\hline Country & $\begin{array}{c}\text { Unemployment } \\
\text { Compensation }\end{array}$ & Total Transfer \\
\hline Belgium & 2.2 & 8.7 \\
Denmark & 3.6 & 11.9 \\
France & 1.6 & 7.0 \\
Germany & 1.5 & 6.0 \\
Ireland & 3.2 & 7.9 \\
Italy & 0.7 & 3.7 \\
Netherlands & 2.8 & 12.7 \\
Norway & 1.4 & 9.9 \\
Spain & 3.2 & 6.7 \\
Sweden & 2.6 & 11.7 \\
U.K. & 1.2 & 8.1 \\
U.S. & 0.7 & 3.2 \\
\hline N.S.
\end{tabular}

Note: Numbers are from Tables 1 and 2 in MacFarlan and Oxley (1996) and are expressed as percentage of GDP.

Table 6: Change in ratio of unemployment compensation to GDP, 1970-1981

\begin{tabular}{lc}
\hline Denmark & 12.1 \\
France & 5.93 \\
Germany & 4.48 \\
Ireland & 1.91 \\
Italy & 3.62 \\
Norway & 3.2 \\
Sweden & 1.95 \\
United Kingdom & 2.92 \\
Europe (average) & 4.51 \\
United States & 1.26 \\
\hline
\end{tabular}

Note: These numbers are from Table 35 in Saunders and Klau (1985). In addition to the U.S., only those European countries are included for which data are based on the complete sample. 
Table 7: Overall tax burden as percentage of GDP

\begin{tabular}{lccc}
\hline & $\mathbf{1 9 6 6 - 7 0}$ & $\mathbf{1 9 7 1 - 7 5}$ & $\mathbf{1 9 7 6 - 8 2}$ \\
\hline Austria & 24.6 & 26.9 & 29.9 \\
Belgium & 34.6 & 38.6 & 44.8 \\
Denmark & 35.5 & 42.9 & 43.7 \\
Finland & 32.0 & 34.4 & 37.1 \\
France & 35.4 & 36.0 & 41.2 \\
Germany & 32.7 & 35.4 & 37.1 \\
Greece & 23.7 & 24.2 & 28.6 \\
Ireland & 29.4 & 31.6 & 35.7 \\
Italy & 28.0 & 28.2 & 33.6 \\
Luxembourg & 30.0 & 34.0 & 39.9 \\
Netherlands & 36.7 & 41.5 & 44.7 \\
Norway & 37.4 & 44.4 & 47.0 \\
Portugal & 20.5 & 22.9 & 28.3 \\
Spain & 16.3 & 18.5 & 23.1 \\
Sweden & 39.0 & 42.4 & 50.0 \\
Switzerland & 22.6 & 26.1 & 31.1 \\
U.K. & 34.6 & 34.3 & 35.7 \\
Europe (average) & 30.2 & 33.1 & 37.1 \\
U.S. & 28.3 & 29.2 & 30.1 \\
\hline
\end{tabular}

Note: These numbers are from Table 56 in Saunders and Klau (1985). 
Figure 1: Tax rates if the economy moves out of high-unemployment steady state

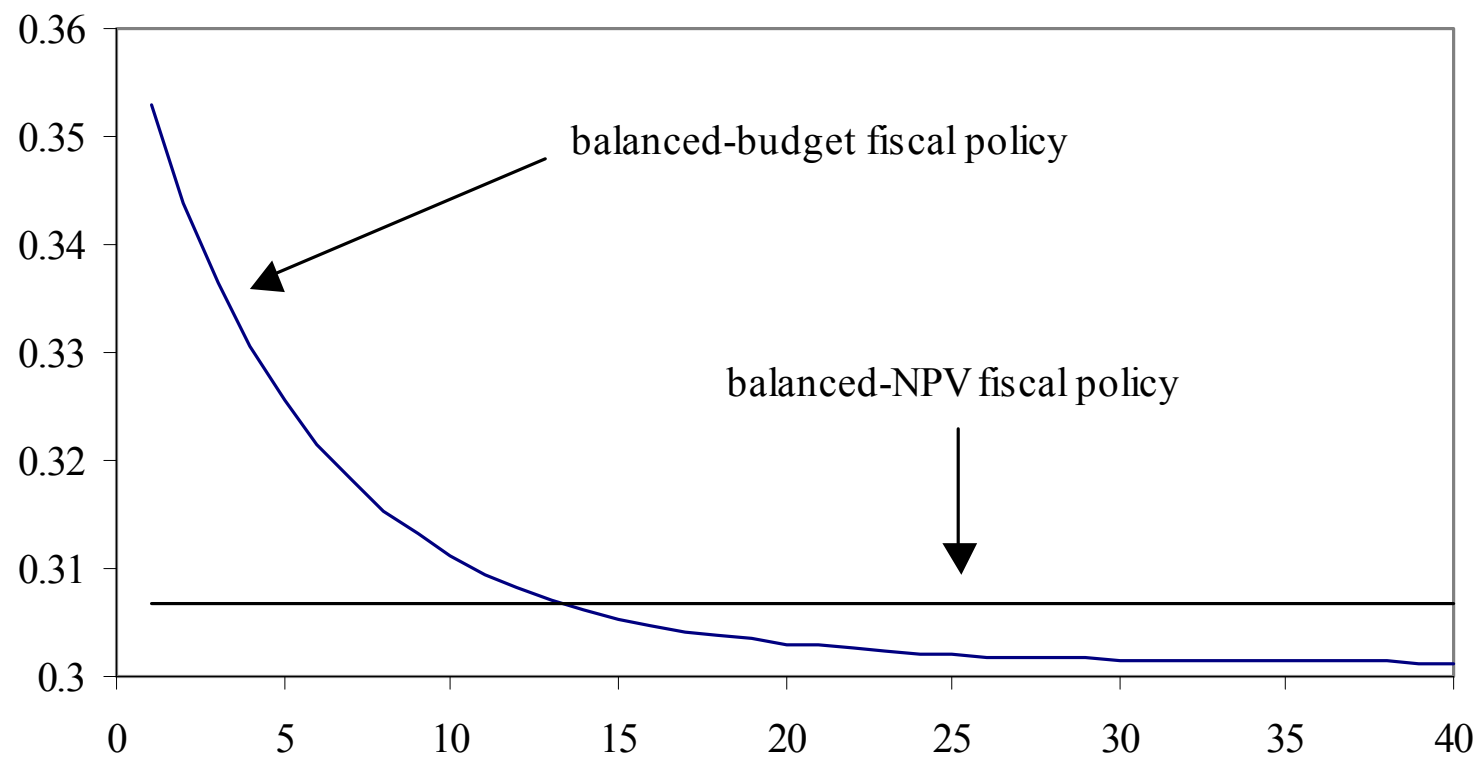


Figure 2: Unemployment rate after a burst of destruction shock

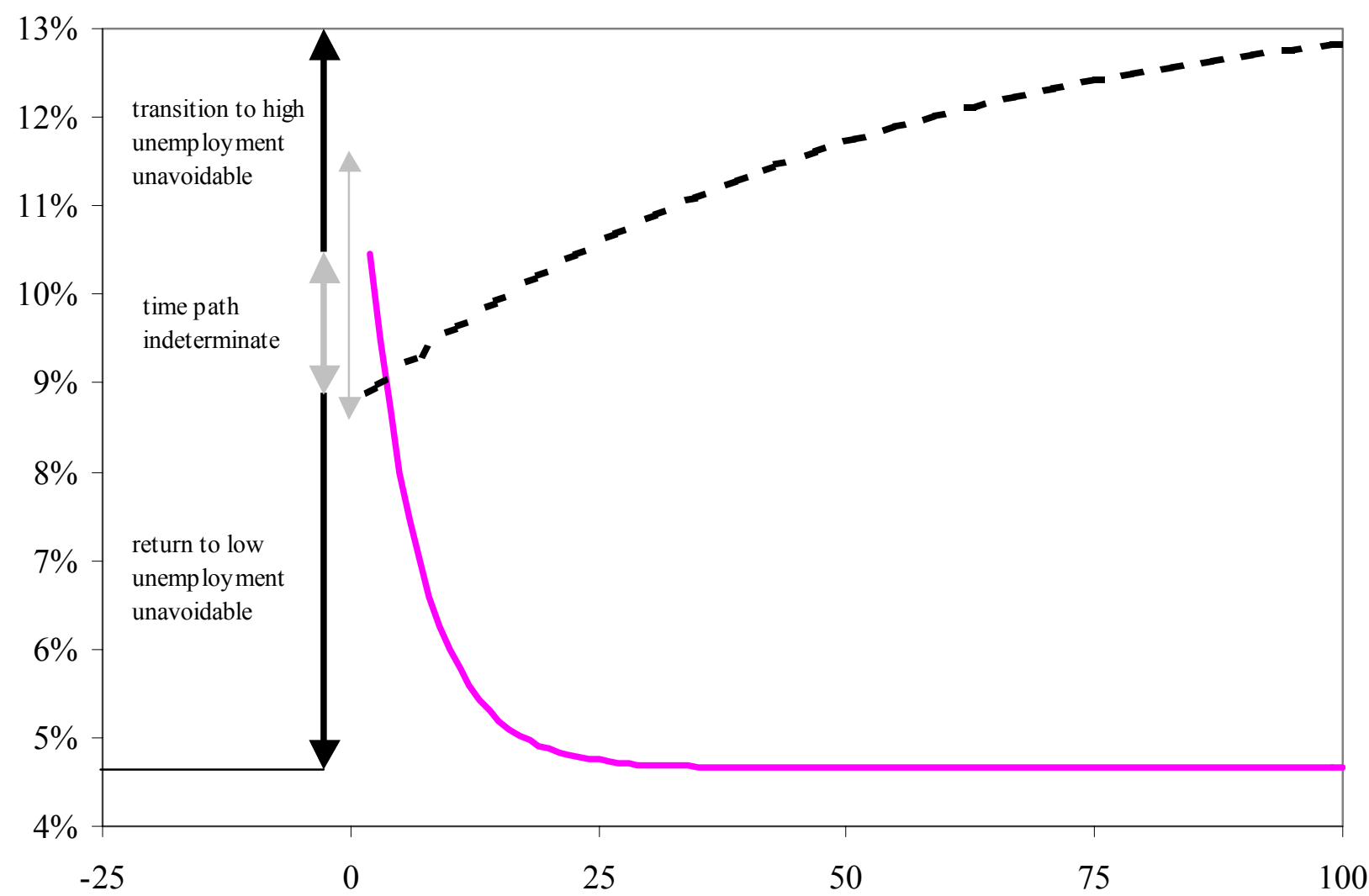

Note: The solid line gives the time path of the unemployment rate for the worst possible shock after which the economy could still move back to the low-unemployment steady state and the dashed line gives the time path of the unemployment rate after the smallest possible shock that is bad enough to make convergence to the high-unemployment steady state a possibility, both under the balanced-budget fiscal policy. The thin double arrow indicates the range of values of the initial unemployment rates for which the economy could move to either steady state under the NPV-balanced fiscal policy after a burst of destruction. 
Figure 3: Unemployment rates

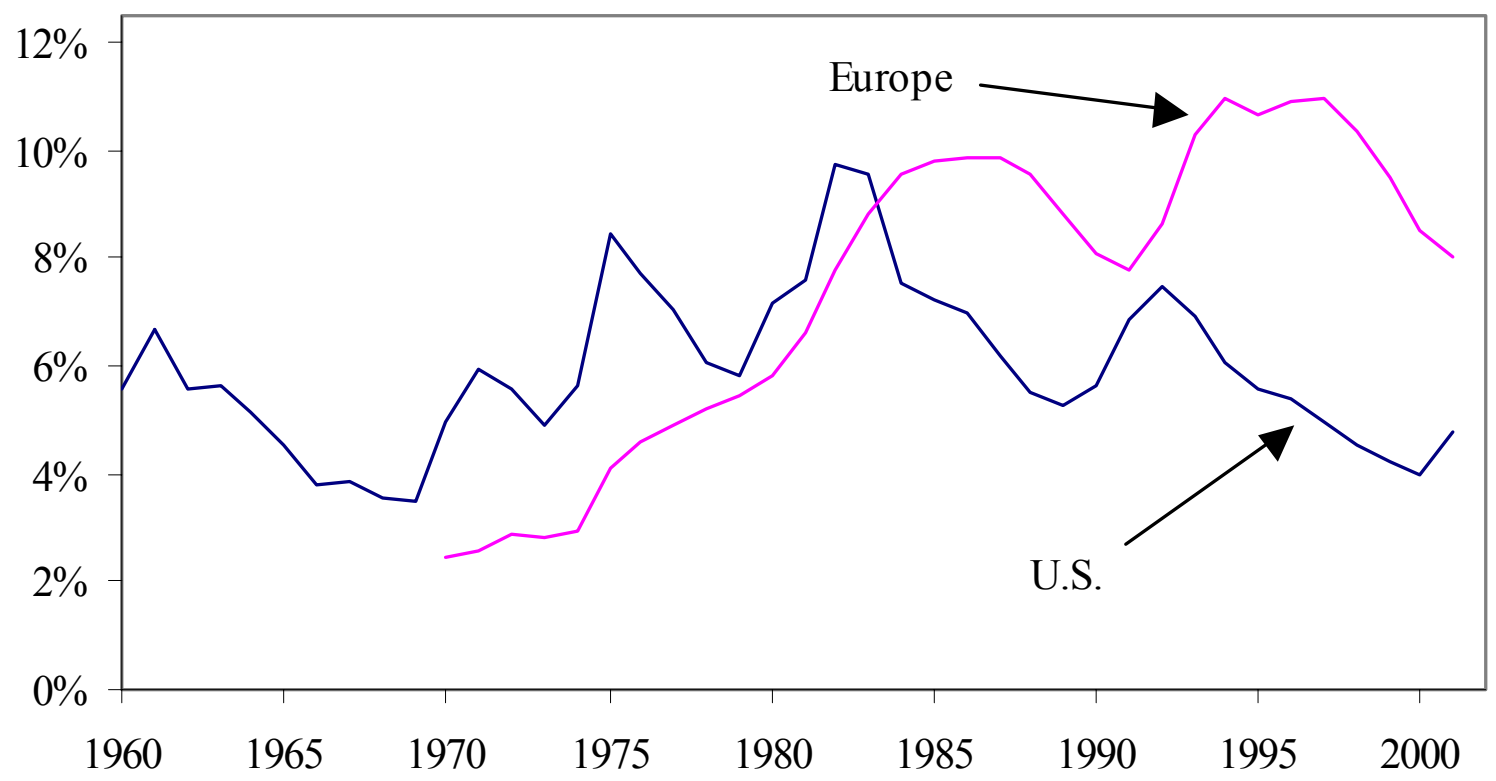

Note: The unemployment rate for Europe is an average of the 15 member countries of the European Union. The data were downloaded from Source-OECD on November 282002. 